\title{
Checkpoint inhibitors in head and neck cancer: current knowledge and perspectives
}

\author{
Bachar Samra, ${ }^{1,2}$ Eric Tam, ${ }^{1,2}$ Babak Baseri, ${ }^{1,2}$ Iuliana Shapira ${ }^{2}$
}

'Department of Hematology/ Oncology, SUNY Downstate Medical Center, Brooklyn, New York, USA 2Department of Hematology/ Oncology, SUNY Downstate Medical Center College of Medicine, Brooklyn, New York, USA

\section{Correspondence to} Dr Bachar Samra,

Department of Hematology/ Oncology, SUNY Downstate Medical Center, Brooklyn, NY 11203, USA; bachar.samra@downstate. edu

\section{An abstract of this} manuscript was presented at the American Federation for Medical Research (AFMR) 2018 Eastern Regional Meeting.

Accepted 27 May 2018 Published Online First 25 June 2018
Check for updates

To cite: Samra B, Tam E, Baseri B, et al. J Investig Med 2018;66:1023-1030.

\section{ABSTRACT}

The emergence of immunotherapy has provided significant clinical improvements in the treatment of metastatic solid tumors. Recurrent/metastatic head and neck squamous cell carcinoma (HNSCC) has dismal prognosis with median survival ranging between 6and12 months. Our aim is to review the current knowledge on the role of the immune system and immune checkpoint inhibitors in HNSCC. We will focus on the landmark trials that led to the regulatory approvals of pembrolizumab and nivolumab, and discuss a few promising contenders in clinical development and highlight the need to identify better biomarkers other than programmed death-ligand 1 to improve patient selection and help predict response.

\section{INTRODUCTION}

Head and neck squamous cell carcinomas (HNSCC) are cancers that comprise the oral cavity, pharynx and larynx, and account for $>90 \%$ of histological subtypes. According to the Surveillance, Epidemiology, and End Results (SEER) data, fewer than two-thirds of patients remain alive at 5 years. ${ }^{1}$ Tobacco has been identified as the most important risk factor, followed by human papilloma virus (HPV), which is primarily seen in oropharyngeal cancers (tonsils and base of the tongue). HPV-associated HNSCC occurs mainly in younger patients, and is associated with longer survival and better treatment outcomes. Current treatment is different depending on stage, goals of care, patient's comorbidities and performance status. In general, patients with localized disease (stage I and II) are treated with single modality local therapy with either surgery or radiation therapy (RT). Patients with locally advanced, non-metastatic disease are typically treated with a multimodality approach with chemotherapy and RT (as organ preservation is preferred) with or without surgery (which can also be done as salvage in recurrent/persistent localized disease). Despite an aggressive multidisciplinary approach, up to $30 \%$ of patients relapse in distant sites, and up to $60 \%$ have local recurrence. ${ }^{2}$ Platinum-based combination chemotherapy with or without cetuximab remains the standard of care (SOC) for relapsed/recurrent and metastatic $(\mathrm{R} / \mathrm{M})$ disease based on the Cetuximab in
First-Line Treatment of Head and Neck Cancer (EXTREME) trial, which showed the addition of cetuximab to platinum/5-fluorouracil (5-FU) chemotherapy improved overall survival (OS) from 7.1 to 10.1 months. ${ }^{3}$ However, toxicity with this regimen is significant, and responses are short. Unfortunately, disease progression, which occurs in many of these patients, seldom responds to further chemotherapy, thus highlighting the need for novel therapies. Multiple factors support the use of immunotherapy in HNSCC, which have prompted the development of clinical studies of immune checkpoint inhibitors (ICI) in HNSCC. We review the rationale for ICI in HNSCC and review the landmark trials that led to regulatory approvals of pembrolizumab and nivolumab, and how to manage their unique toxicities. We also provide an overview of current trials in clinical development and we highlight the need for predictors of response to these novel agents.

\section{THE ROLE OF IMMUNE SYSTEM AND CHECKPOINT PATHWAY IN HNSCC}

HNSCC is characterized by immune evasion strategies in an immunosuppressive microenvironment and leads to tumor progression unchecked by the immune system. ${ }^{4}$ Tumor evasion and immune dysfunction have been associated with several mechanisms and are well described in the literature. ${ }^{5} 6$ FoxP3+ Tregulatory (Treg) cells are known to have an immunoregulatory effect through interleukin-10 and transforming growth factor- $\beta$, causing suppression and downregulation of proliferation of CD4+ and CD $8+$ Tcells, as well as inducing apoptosis. Treg cells are found in high levels in HNSCC, which downregulate cytokine expression and may be responsible for antitumor response. ${ }^{78}$ Tumor cells also appear to have decreased HLA class I expression with tumor-associated antigens, which allows for evasion of the adaptive immune system and T cells. ${ }^{10}$ Other mechanisms act to alter the tumor microenvironment by favoring immunosuppressive cells including myeloid-derived suppressive cells (MDSC) and tumor-associated macrophages. These cells cause an increase in pro-inflammatory cytokines and subsequent activation of signal transducer and activator of transcription 3 pathway, ultimately promoting tumor growth. ${ }^{11}$ 


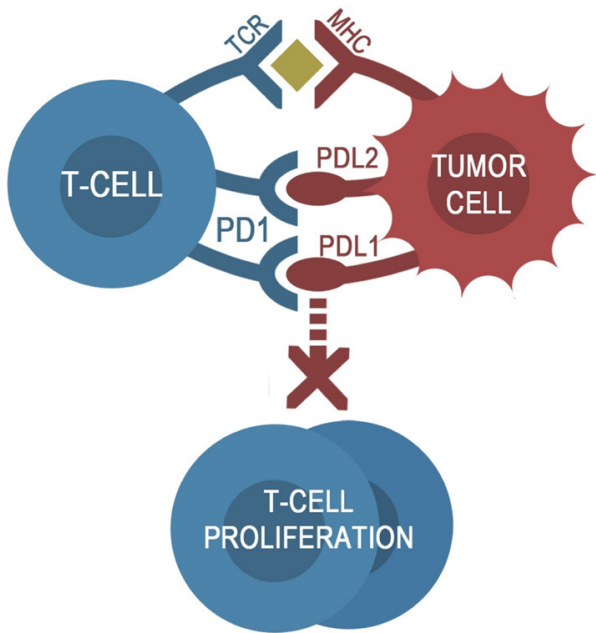

Figure 1 Programmed death-ligand 1 (PD-L1)/PD-L2 costimulatory pathway. Tumor cell expression of PD-L1/PD-L2 results in binding PD1 to PD-L1/PD-L2, inhibiting T-cell activation and proliferation. MHC, major histocompatibility complex; TCR, T-cell receptor.

A relatively newer therapeutic target involves the immune checkpoint inhibitors. Programmed death-ligand 1 (PD-L1) and cytotoxic T-lymphocyte antigen 4 (CTLA-4) normally regulate immune responses by effector $\mathrm{T}$ cells to prevent autodamage. Levels of PD-L1 and CTLA-4 are found to be increased in HNSCC, thus providing an additional pathway for immune evasion by inactivation of $\mathrm{T}$ cells, even when presented with tumor-associated antigen. ${ }^{12}$ PD-1 binding suppresses T-cell receptor (TCR) signals and induces T-cell inactivation by preventing phosphorylation of TCR signaling intermediates. Prolonged T-cell activation, such as what is seen in chronic HPV infections, can cause upregulation of PD-1 expression contributing to the 'exhausted' phenotype of inactive T cells. ${ }^{13} \mathrm{PD}-\mathrm{L} 1$ and PD-L2 expressions are

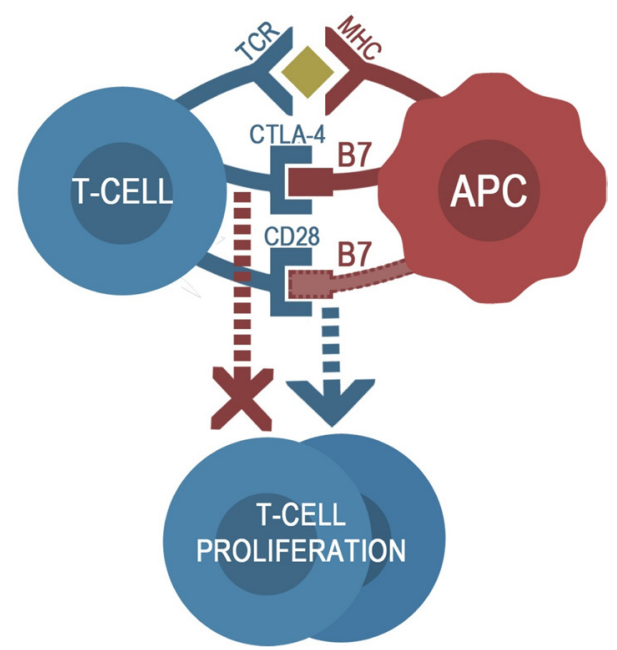

Figure 2 Cytotoxic T-lymphocyte antigen 4 (CTLA-4) costimulatory pathway. Normal B7-CD28 binding activates T-cell proliferation. CTLA-4 is a homolog to CD28, which competitively and preferentially binds to $B 7$, preventing $C D 28$ binding and T-cell activation. APC, antigen-presenting cells; MHC, major histocompatibility complex; TCR, T-cell receptor. frequently elevated in HNSCC tumor and immune cells, particularly HPV-positive patients. ${ }^{14}$

In contrast to PD-L1 pathway, which occurs in the tumor microenvironment, CTLA-4 regulation occurs primarily in lymphoid tissue. CTLA-4 is expressed on activated T cells and binds to CD80 and CD86 on antigen-presenting cells (APC). TCR binding to major histocompatibility complex (MHC) on APCs provide T-cell activation but requires costimulatory signals provided by B7 on APCs and CD28 on T cells. ${ }^{15}$ CTLA-4 is a homolog to CD28 and binds to B7 with higher affinity than CD28. When CTLA-4 binds to $\mathrm{B} 7$ and prevents $\mathrm{B} 7$ binding to CD28, there is insufficient costimulatory signal and the $\mathrm{T}$ cell is not activated. These findings prompted the development of clinical studies of ICI in HNSCC. Figures 1 and 2 illustrate PD-L1 and CTLA-4 pathways, respectively.

\section{IMMUNE CHECKPOINT INHIBITORS}

The past 2 years have witnessed the approvals of nivolumab and pembrolizumab in patients with HNSCC who have progressed on, or following, platinum-based chemotherapy. Nivolumab has increased OS compared with chemotherapy, ${ }^{16}$ and has a category 1 recommendation from the National Cancer Committee Network based on high level of evidence, whereas pembrolizumab has a category $2 \mathrm{a}$ recommendation based on non-randomized trials. ${ }^{17} 18$ Interestingly, the recently published phase III randomized trial failed to show superiority of pembrolizumab compared with chemotherapy. ${ }^{19}$ Despite the variable utility of PD-L1 status as a biomarker of response across trials, a higher PD-L1 expression seems to be associated with greater survival benefit with nivolumab and increased responses and perhaps survival with pembrolizumab. Finding a better/ more reliable biomarker remains an unmet goal in order to improve patient selection, maximize efficacy and predict response.

\section{Pembrolizumab}

Pembrolizumab (MK-3475) is a humanized IgG4 monoclonal antibody against PD-1. The safety and efficacy of pembrolizumab was initially assessed in the HNSCC cohort of the phase Ib open-label trial KEYNOTE-012 (which included patients with different advanced refractory solid tumors). ${ }^{20}$ Clinical and durable antitumor activity was shown in PD-L1-positive patients at the dose of $10 \mathrm{mg} / \mathrm{kg}$ every 2 weeks. PD-L1 positivity was defined by both tumor and immune cell expression $\geq 1 \%$. Thereafter, a fixed dose of $200 \mathrm{mg}$ every 3 weeks was studied in the expansion cohort of 132 patients with R/M HNSCC irrespective of biomarker or HPV status. ${ }^{17}$ The fixed and less frequent dose regimen conferred multiple advantages including safety, convenience, reduction of waste and adherence. Most patients were heavily pretreated $(57 \%$ had at least two prior therapies) and $78 \%$ of patients were PD-L1 positive. The overall objective response rate (ORR) was $20 \%$ and the 6-month OS rate was 59\%. Pembrolizumab was well tolerated with the majority of adverse events (AE) reported as grade 1/2 (59.8\%); fatigue being the most common. Grade 3/4 immune-related AEs, especially pneumonitis, were relatively infrequent $(<4 \%)$. Based on these findings, the Food and Drug Administration (FDA) granted pembrolizumab 
accelerated approval in August 2016 for patients with R/M HNSCC with disease progression on, or after, platinum-containing chemotherapy. Recently, KEYNOTE-055, a phase II single-arm study, evaluated pembrolizumab in 171 patients with R/M HNSCC refractory to platinum and cetuximab. ${ }^{18}$ Median age was 61 and three-quarters of patients had received at least two prior therapies. Eighty-two per cent of patients were PD-L1-positive, and $22 \%$ were HPV-positive. ORR, comprising complete response (CR) and partial response (PR), was 16\%, all of which but one were PR. Stable disease (SD) was achieved in 19\%. Responses were similar regardless of HPV or PD-L1 status $(16 \%$ in HPV-positive vs $15 \%$ in HPV-negative disease, and 18\% in PD-L1-positive vs 12\% in PD-L1-negative patients). Median duration of response (DoR) was 8 months overall and significantly longer in HPV -positive responders compared with HPV-negative responders (not reached vs 7 months). Median progression-free survival (PFS) and OS were 2.1 and 8 months, respectively, with no significant difference between all PD-L1 and HPV subgroups. The majority of AEs were of grade 1 and 2 . Grade 3 or more AEs occurred in 15\%, and led to discontinuation of treatment in $4 \%$ of patients. One patient died of immune-mediated pneumonitis. The most common immune-mediated AEs included hypothyroidism (16\%), pneumonitis $(4 \%)$ and hyperthyroidism (2\%). Based on the acceptable toxicity and significant efficacy in the two trials above, a randomized controlled phase III trial was conducted to compare pembrolizumab with standard chemotherapy in $\mathrm{R} / \mathrm{M}$ HNSCC after failure of platinum-based chemotherapy (KEYNOTE-040). The results were presented at the European Society of Medical Oncology (ESMO) 2017 Congress. ${ }^{21}$ Four hundred ninety-five patients were equally randomized to either pembrolizumab or standard chemotherapy (investigator choice of methotrexate, docetaxel or cetuximab). Pembrolizumab failed to meet the primary end point of OS (8.4 vs 7.1 months, HR $0.81, p=0.0204$ ). However, subset analysis showed more significant benefit with increased PD-L1 expression (see 'predictive biomarkers of response' section for further details). The safety profile favored pembrolizumab in all subgroups except hypothyroidism, which occurred in $13 \%$ with pembrolizumab vs $1 \%$ in chemotherapy arm.

\section{Nivolumab}

Nivolumab is a fully human IgG4 monoclonal antibody against PD-1. In two pivotal phase I trials in advanced solid tumors, nivolumab showed significant clinical antitumor activity and was relatively well tolerated at an escalated dose of $10 \mathrm{mg} / \mathrm{kg}$ once every 2 weeks. ${ }^{22}{ }^{23}$ This led to a randomized phase III trial of nivolumab in platinum-refractory R/M HNSCC (CheckMate-141). ${ }^{16}$ Three hundred sixty-one patients were assigned in a 2:1 ratio to either nivolumab (at a dose of $3 \mathrm{mg} / \mathrm{kg}$ of body weight once every 2 weeks) or investigator's choice of single agent standard chemotherapy (methotrexate, docetaxel or cetuximab); $54.6 \%$ of patients had at least two prior lines of systemic therapy. PD-L1 expression was evaluated by immunohistochemistry by a rabbit antihuman PD-L1 antibody and was scored at prespecified expression levels $(\geq 1 \%, \geq 5 \%$ and $\geq 10 \%$ in a minimum of 100 tumor cells that could be evaluated). The trial was terminated early after meeting its primary end point. Median OS was superior in the nivolumab group (7.5 vs 5.1 months $(\mathrm{HR}=0.70, \mathrm{p}=0.01)$ and was more than double at 1 year (36\% vs $16.6 \%)$. ORR was also superior with nivolumab (13.3\% vs 5.8\%). Median PFS was similar in both groups (2 vs 2.3 months). However, PFS was interestingly higher at 6 months for nivolumab (19.7\% vs 9.9\%) based on the late separation of the PFS curves, which likely reflects the longer DoR seen with nivolumab. Regarding safety profile, nivolumab was better tolerated than chemotherapy with grade 3 or higher AEs reported in $13.1 \%$ vs $35.1 \%$, respectively. Most common AEs were fatigue (14.0\%), nausea $(8.5 \%)$ and rash $(7.6 \%)$; the most common grade 3 or 4 events were fatigue $(2.1 \%)$ and anemia (1.3\%). Furthermore, an exploratory analysis proved that nivolumab was superior in terms of health-related quality of life. ${ }^{24}$ This trial has led to the FDA approval of nivolumab in November 2016 for the treatment of patients with $\mathrm{R} / \mathrm{M}$ HNSCC with disease progression on, or after, a platinum-based therapy. Table 1 summarizes the findings of completed trials for both pembrolizumab and nivolumab in HNSCC.

\section{Other agents}

Alternative targets for immune checkpoint inhibition exist in PD-L1 and CTLA-4 axis. Durvalumab (MEDI4736) is an IgG1 antibody against PD-L1 on tumor cells and seems to have similar efficacy and toxicity to the previously mentioned agents. In an open-label phase I/II trial including multiple advanced solid malignancies (NCT01693562), 62 patients with R/M HNSCC received durvalumab every 2 weeks intravenously at $10 \mathrm{mg} / \mathrm{kg}$ for 12 months. Preliminary results were reported at the ESMO 2016 Congress. ${ }^{25}$ Six-month and 12 -month OS were $62 \%$ and $42 \%$, respectively, and responses were durable (>12 months in 6/7 responders). Although ORR was higher in PD-L1-positive patients ( $25 \%$ vs $12 \%$ overall), no significant difference in OS was seen by PD-L1 status. Fatigue was the most common $\mathrm{AE}(18 \%)$, and grade $\geq 3$ AEs occurred in only $8 \%$. Additionally, durvalumab is being evaluated as monotherapy in platinum-refractory, PD-L1-positive R/M HNSCC in phase II trial (HAWK; NCT02207530). Preliminary results for 111 evaluated patients were recently presented at the ESMO 2017 Congress. ${ }^{26}$ PD-L1 positivity was different than for other ICI and was defined by the staining of at least $25 \%$ of tumor cells. ORR was $16.2 \%$ but higher in HPV-positive patients compared with HPV-negative counterparts $(29.4 \%$ vs $10.8 \%)$. The disease control rate at 24 weeks $(\mathrm{CR}+\mathrm{PR}+\mathrm{SD})$ was $23.4 \%$. Overall, median PFS was 2.1 months, median OS was 7.1 months and the 12-month survival rate was $33.6 \%$. Grade 3 or more AEs occurred in only $8 \%$ and there was no death due to treatment-related AEs.

Avelumab is a fully human monoclonal anti-PD-L1 antibody characterized by an antibody-dependent cell-mediated cytotoxicity. Avelumab is being evaluated either as monotherapy or in combination with other therapies in locally advanced and metastatic HNSCC.

Ipilimumab is a monoclonal antibody against CTLA-4. To date, no results have been reported for ipilimumab in HSNCC. Targeting both PD-L1 and CTLA-4 pathways 
Table 1 Completed trials for pembrolizumab and nivolumab in R/M HNSCC and their major findings

\begin{tabular}{|c|c|c|c|c|c|c|c|c|}
\hline Trial & Phase & Sample size & Setting & Arms & $\begin{array}{l}\text { Primary } \\
\text { end points }\end{array}$ & Major findings & $\begin{array}{l}\text { Effect of HPV } \\
\text { status }\end{array}$ & $\begin{array}{l}\text { Effect of PD-L1 } \\
\text { expression }\end{array}$ \\
\hline KEYNOTE-012 & lb & 132 & $\begin{array}{l}\text { Advanced solid } \\
\text { tumors. Cohort } \\
\text { B2: R/M HNSCC }\end{array}$ & $\begin{array}{l}\text { Pembrolizumab } \\
200 \text { mg once every } 3 \\
\text { weeks }\end{array}$ & $\begin{array}{l}\text { Safety and } \\
\text { efficacy }\end{array}$ & $\begin{array}{l}\text { ORR 20\% } \\
\text { Overall, } 6 \text {-month } \\
\text { OS was } 59 \%\end{array}$ & $\begin{array}{l}\text { 6-month OS } \\
\text { was } 70 \% \text { in } \\
\mathrm{HPV}+\text { and } 56 \% \\
\text { in HPV- patients }\end{array}$ & $\begin{array}{l}\text { Higher OS for } \\
\text { patients with PD- } \\
L 1 \geq 1 \% \text { (303 vs } \\
151 \text { days) }\end{array}$ \\
\hline KEYNOTE-055 & II & 171 & $\begin{array}{l}\text { R/M HNSCC } \\
\text { refractory to } \\
\text { platinum and } \\
\text { cetuximab }\end{array}$ & $\begin{array}{l}\text { Pembrolizumab } \\
200 \text { mg once every } 3 \\
\text { weeks }\end{array}$ & ORR and safety & $\begin{array}{l}\text { ORR } 16 \% \\
\text { Median DoR } \\
8 \text { months } \\
\text { Median OS } \\
8 \text { months }\end{array}$ & $\begin{array}{l}\text { Similar ORR but } \\
\text { higher OS for } \\
\text { HPV+ }\end{array}$ & $\begin{array}{l}\text { Increased ORR } \\
\text { without affecting OS } \\
\text { or PFS }\end{array}$ \\
\hline KEYNOTE-040 & III & 495 & $\begin{array}{l}\text { Platinum- } \\
\text { refractory R/M } \\
\text { HNSCC }\end{array}$ & $\begin{array}{l}\text { Pembrolizumab } \\
200 \text { mg once every } 3 \\
\text { weeks vs } \\
\text { investigator choice of } \\
\text { either methotrexate, } \\
\text { docetaxel or } \\
\text { cetuximab }\end{array}$ & OS & $\begin{array}{l}\text { Non-statistically } \\
\text { significant } \\
\text { improvement } \\
\text { in OS ( } 8.4 \text { vs } \\
7.1 \text { months, } \\
p=0.204 \text { ) }\end{array}$ & Not reported & $\begin{array}{l}\text { Increased OS } \\
\text { with higher PD-L1 } \\
\text { expression }\end{array}$ \\
\hline CheckMate-141 & III & 361 & $\begin{array}{l}\text { Platinum- } \\
\text { refractory R/M } \\
\text { HNSCC }\end{array}$ & $\begin{array}{l}\text { Nivolumab } 3 \mathrm{mg} / \mathrm{kg} \\
\text { once every } 2 \text { weeks vs } \\
\text { investigator choice of } \\
\text { either methotrexate, } \\
\text { docetaxel or } \\
\text { cetuximab }\end{array}$ & OS & $\begin{array}{l}\text { OS benefit for } \\
\text { nivolumab: } 7.5 \\
\text { vs. } 5.1 \text { months } \\
(H R=0.70 \text {, } \\
p=0.01)\end{array}$ & $\begin{array}{l}\text { Better OS benefit } \\
\text { for P16+ disease }\end{array}$ & $\begin{array}{l}\text { OS benefit in PD- } \\
\mathrm{L} 1>1 \%\end{array}$ \\
\hline
\end{tabular}

ORR, overall response rate; OS, overall survival; PD-L1, programmed death-ligand 1; PFS, progression-free survival; R/M HNSCC, recurrent/metastatic head and neck squamous cell carcinoma.

may have synergistic antitumor activity by potentiating the immune effect. This combination strategy has shown consistent efficacy in advanced melanoma ${ }^{27}$ and metastatic renal cell carcinoma. ${ }^{28}$ CheckMate 651 is a phase III trial comparing nivolumab and ipilimumab combination with standard chemotherapy (cetuximab+cisplatin/ carboplatin +5-FU) as first-line treatment in R/M HNSCC. CheckMate 741 is a phase II trial comparing nivolumab monotherapy with nivolumab+ipilimumab.

Tremelimumab is a selective human IgG2 monoclonal antibody of CTLA-4. Given the promising results from a pivotal phase I trial in non-small lung cancer where the combination of durvalumab and tremelimumab showed tolerable and meaningful clinical efficacy, this combination is also being explored in HNSCC. Two phase III studies are currently evaluating durvalumab with and without tremelimumab compared with SOC chemotherapy as firstline therapy in R/M HNSCC (EAGLE NCT02369874 and KESTREL NCT02551159). Select ongoing trials of ICI in HNSCC in two different settings (R/M and locoregional) are presented in table 2 and table 3 , respectively.

\section{COMBINATION THERAPY}

While the use of cytotoxic and targeted agents can alter the expression of checkpoint receptors, their effects on the immune system and HNSCC tumor cells remain complex and poorly understood. For instance, cetuximab has been shown to increase CTLA $-4^{+}$Foxp $3^{+}$Treg suppressor cells in the circulation and in the microenvironment, suggesting that the addition of ipilimumab may eliminate this suppressive effect and promote antitumor immunity. ${ }^{29}$ Similarly, in HPV-positive oropharyngeal squamous cell carcinoma, chemoradiation has been shown to upregulate PD- 1 expression on CD4+ T cells and to increase peripheral MDSC, antagonizing antitumor and anti-HPV immunity, and suggesting that PD-1 blockade can have a positive effect. ${ }^{30}$ Conversely, cetuximab can exert a positive antitumor immunogenic response by promoting dendritic cell maturation and cytotoxic T-cell priming, which would enhance adaptive immune responses. In addition, select chemotherapy agents can potentiate T-cell-dependent antitumor immunity by inducing apoptosis in MDSCs $(5-\mathrm{FU}),{ }^{31}$ or by inducing apoptosis in immunosuppressive Tregs (cyclophosphamide). ${ }^{32}$ Therefore, the interactions between therapeutic agents and tumor microenvironment are far from being fully delineated. Nonetheless, they provide a rationale for combining checkpoint inhibitors with conventional treatments. Targeting CTLA-4 and PD-1/ PD-L1 axis in this setting allows for lifting of inhibitory signals on effector T lymphocytes in the tumor microenvironment, which then allows therapeutic synergy with cytotoxic or targeted agents. In the R/M setting, pembrolizumab alone or in combination with fluorouracil/platinum versus the SOC, that is, EXTREME trial regimen (cetuximab + platinum $+5-\mathrm{FU}$ ) is currently being investigated in a phase III trial (NCT02358031) and results are eagerly awaited. Furthermore, synergy between ICI and RT, both inside and outside of the radiation field (known as an abscopal effect) has been documented in different tumors in both mouse models and in humans. ${ }^{33}$ Exposure of cancer cell neoantigens following radiation-induced cell death leads to priming of $\mathrm{T}$ cells, which can in turn cause tumor regression in distant sites outside of radiation field, potentiated by the action of checkpoint inhibitors. Another therapeutic combination strategy involves the use of HPV vaccines with checkpoint inhibitors. Preclinical models 
Table 2 Select ongoing trials for checkpoint inhibitors in R/M HNSCC

\begin{tabular}{|c|c|c|c|c|c|}
\hline $\begin{array}{l}\text { Immune checkpoint } \\
\text { inhibitor }\end{array}$ & Trial/identifier & Phase & Setting & Intervention/drug & $\begin{array}{l}\text { Primary } \\
\text { end point }\end{array}$ \\
\hline Pembrolizumab & $\begin{array}{l}\text { NCT02358031 } \\
\text { (KEYNOTE-048) }\end{array}$ & III & $\begin{array}{l}\text { R/M HNSCC first line, } \\
\text { or }>6 \text { months after } \\
\text { last therapy for locally } \\
\text { advanced disease }\end{array}$ & $\begin{array}{l}\text { Pembrolizumab vs pembrolizumab+platinum/5-FU vs } \\
\text { cetuximab+platinum/5-FU }\end{array}$ & PFS and OS \\
\hline Pembrolizumab & NCT03082534 & ॥ & R/M HNSCC & Pembrolizumab+cetuximab & ORR \\
\hline Pembrolizumab & NCT02454179 & $\|$ & $\begin{array}{l}\text { Platinum-refractory R/M } \\
\text { or unresectable HNSCC }\end{array}$ & Pembrolizumab \pm acalabrutinib & ORR \\
\hline Pembrolizumab & NCT02892201 & II & $\begin{array}{l}\text { HNSCC with residual } \\
\text { disease after definitive } \\
\text { RT ( } \pm \text { chemo) }\end{array}$ & Pembrolizumab & ORR \\
\hline Pembrolizumab & $\begin{array}{l}\text { NCT02626000 (MASTERKEY } \\
\text { 232/KEYNOTE-137) }\end{array}$ & $\mathrm{Ib} / \mathrm{lll}$ & R/M HNSCC & Pembrolizumab+talimogene laherparepvec & DLT \\
\hline Nivolumab & $\begin{array}{l}\text { NCT02741570 (CheckMate } \\
651 \text { ) }\end{array}$ & III & $\begin{array}{l}\text { R/M HNSCC, first-line } \\
\text { therapy }\end{array}$ & $\begin{array}{l}\text { Nivolumab+ipilomumab vs SOC } \\
\text { (cetuximab+cisplatin/carboplatin+5-FU) }\end{array}$ & OS and PFS \\
\hline Nivolumab & $\begin{array}{l}\text { NCT02823574 (CheckMate } \\
\text { 714) }\end{array}$ & II & R/M HNSCC & Nivolumab+ipilimumab vs nivolumab alone & $\begin{array}{l}\text { ORR and DoR } \\
\text { in platinum- } \\
\text { refractory } \\
\text { subgroup }\end{array}$ \\
\hline Durvalumab & NCT02207530 & II & $\begin{array}{l}\text { PD-L1-positive, } \\
\text { platinum-refractory R/M } \\
\text { HNSCC }\end{array}$ & Durvalumab & ORR \\
\hline Durvalumab & NCT02551159 (KESTREL) & III & $\begin{array}{l}\text { R/M HNSCC, first-line } \\
\text { therapy }\end{array}$ & $\begin{array}{l}\text { Durvalumab } \pm \text { tremelimumab vs SOC (EXTREME } \\
\text { regimen) }\end{array}$ & PSF and OS \\
\hline Durvalumab & NCT02369874 & III & $\begin{array}{l}\text { R/M HNSCC, first-line } \\
\text { therapy }\end{array}$ & Durvalumab \pm tremelimumab vs $\mathrm{SOC}$ & PFS and OS \\
\hline Durvalumab & NCT02499328 & $\mathrm{lb} / \mathrm{ll}$ & $\begin{array}{l}\text { R/M HNSCC, second-line } \\
\text { therapy }\end{array}$ & $\begin{array}{l}\text { AZD9150 and AZD5069_-both as monotherapy and } \\
\text { in combination with durvalumab }\end{array}$ & $\begin{array}{l}\text { MTD, safety and } \\
\text { tolerability and } \\
\text { ORR }\end{array}$ \\
\hline Durvalumab & NCT03162224 & $\mathrm{lb} / \mathrm{ll}$ & $\begin{array}{l}\text { HPV-associated R/M } \\
\text { HNSCC }\end{array}$ & $\begin{array}{l}\text { Durvalumab+MEDI0457 (INO-3112), which is an HPV } \\
\text { DNA vaccine }\end{array}$ & Safety and efficacy \\
\hline Avelumab & $\begin{array}{l}\text { NCT01772004 (JAVELIN solid } \\
\text { tumor) }\end{array}$ & 1 & $\begin{array}{l}\text { Metastatic or locally } \\
\text { advanced solid tumors }\end{array}$ & Avelumab & $\begin{array}{l}\text { DLT and confirmed } \\
\text { best overall } \\
\text { response }\end{array}$ \\
\hline Avelumab & NCT03260023 & $\mathrm{lb} / \mathrm{ll}$ & $\begin{array}{l}\text { HPV } 16 \text { positive R/M } \\
\text { cancers and expansion } \\
\text { cohort to OPC }\end{array}$ & Avelumab+TG4001 & $\begin{array}{l}\text { Safety and } \\
\text { tolerability }\end{array}$ \\
\hline Ipilimumab & NCT01935921 & 1 & $\begin{array}{l}\text { Previously untreated } \\
\text { stage III/IV HNSCC }\end{array}$ & Ipilimumab+cetuximab+IMRT & DLT \\
\hline
\end{tabular}

DLT, dose-limiting toxicity; DoR, duration of response; HPV, human papilloma virus; IMRT, intensity-modulated radiotherapy; OS, overall survival; PD-L1, programmed death-ligand 1; ORR, overall response rate; PFS, progression-free survival; OPC, oropharyngeal cancer; SOC, standard of care; RT, radiation therapy; R/M HNSCC, recurrent/metastatic head and neck squamous cell carcinoma; 5-FU, 5-fluorouracil.

have shown more potent antitumor responses when anti-PD-1 therapy was combined with vaccines against HPV-specific antigens. ${ }^{34}$ Multiple trials are currently underway combining ICI with different HPV vaccines (ISA101/adjuvant montanide, MEDI0457, ADXS11011 and TG4001). In locally advanced and untreated intermediate-risk to high-risk HNSCC, trials are incorporating ICI in cetuximab/radiotherapy protocols or platinum-based chemoradiation protocols (table 3). These trials will evaluate combination therapies in both upfront and adjuvant settings, and will compare the sequencing of checkpoint inhibitors in relation to radiation therapy. Killer-cell immunoglobulin-like receptors (KIR) are other checkpoint receptors that suppress cytotoxic effects of natural killer (NK) cells on HLA-expressing tumor cells. Inhibition of these receptors could remove inhibitory signals on NK cells and further assist with antitumor immunogenic response.
Two trials are investigating the combination of ipilimumab (NCT01750580) or nivolumab (NCT01714739) with anti-KIR antibody. Additionally, CD137 and OX40 are costimulatory tumor necrosis factor superfamily receptors primarily expressed on activated $\mathrm{T}$ cells, with OX40 also present on dendritic and activated NK cells. They both stimulate T-cell proliferation and enhance antitumor eradication. ${ }^{35} 36$ Therefore, stimulation of these receptors with monoclonal antibodies represents a future therapeutic target (with anti-OX40 and antiCD137 agonists) in HNSCC. ${ }^{37}$ Lymphocyte activation gene-3 (LAG-3) is another immune checkpoint protein that negatively regulates $T$ cells and immune response by binding to MHC class II molecules, and has been found to be overexpressed in HNSCC. ${ }^{38}$ Monoclonal antibodies against LAG-3 are also being explored in multiple trials in HNSCC. Other trials include combinations of PD- 1 inhibitors with CTLA-4 inhibitors, 


\begin{tabular}{|c|c|c|c|c|c|}
\hline $\begin{array}{l}\text { Immune checkpoint } \\
\text { inhibitor }\end{array}$ & Trial/identifier & Phase & Setting & Intervention/drug & Primary end point \\
\hline Pembrolizumab & $\begin{array}{l}\text { NCT03040999 } \\
\text { (KEYNOTE-412) }\end{array}$ & III & Locally advanced HNSCC & $\begin{array}{l}\text { Pembrolizumab or placebo, concomitantly } \\
\text { and as maintenance+chemoRT (cisplatin } \\
\text { once every } 3 \text { weeks) }\end{array}$ & EFS \\
\hline Pembrolizumab & NCT02289209 & II & $\begin{array}{l}\text { Locoregional inoperable } \\
\text { recurrence/second primary }\end{array}$ & Reirradiation+pembrolizumab & PFS \\
\hline Pembrolizumab & NCT02609503 & II & $\begin{array}{l}\text { Locally advanced HNSCC, not } \\
\text { cisplatin eligible }\end{array}$ & Pembrolizumab+IMRT & PFS at 20 weeks \\
\hline Pembrolizumab & NCT02759575 & I/II & Locally advanced HNSCC & $\begin{array}{l}\text { Pembrolizumab+cisplatin (once every } 3 \\
\text { weeks)+RT }\end{array}$ & $\begin{array}{l}\text { AEs and laryngectomy-free } \\
\text { survival }\end{array}$ \\
\hline Pembrolizumab & $\begin{array}{l}\text { NCT02841748 } \\
\text { (PATHWay study) }\end{array}$ & II & $\begin{array}{l}\text { HNSCC at high risk of } \\
\text { recurrence }\end{array}$ & Adjuvant pembrolizumab vs placebo & $\begin{array}{l}\text { PFS } \\
\text { (at } 2 \text { years) }\end{array}$ \\
\hline Pembrolizumab & NCT02777385 & II & $\begin{array}{l}\text { Intermediate or high-risk } \\
\text { locally advanced HNSCC }\end{array}$ & $\begin{array}{l}\text { Concurrent or sequential pembrolizumab in } \\
\text { combination with cisplatin+IMRT }\end{array}$ & 1-year PFS and acute toxicity \\
\hline Pembrolizumab & NCT03057613 & II & $\begin{array}{l}\text { High-risk resected cutaneous } \\
\text { HNSCC }\end{array}$ & Pembrolizumab+postoperative radiation & DLT and PFS (at 1 year) \\
\hline Pembrolizumab & NCT02586207 & $\mathrm{lb}$ & Locally advanced HNSCC & Pembrolizumab+weekly cisplatin+RT & AEs \\
\hline Nivolumab & NCT02764593 & I & $\begin{array}{l}\text { Intermediate and high-risk } \\
\text { locoregionally advanced } \\
\text { HNSCC }\end{array}$ & $\begin{array}{l}\text { Addition of nivolumab to either cisplatin- } \\
\text { based chemoRT, or cetuximab+RT or IMRT }\end{array}$ & DLT \\
\hline Durvalumab & $\begin{array}{l}\text { NCT02997332 } \\
\text { (MEDINDUCTION) }\end{array}$ & I & Locally advanced HNSCC & Durvalumab+docetaxel+cisplatin+5-FU & $\begin{array}{l}\text { Recommended phase II dose, } \\
\text { DLT }\end{array}$ \\
\hline Avelumab & $\begin{array}{l}\text { NCT02952586 } \\
\text { (JAVELIN head and } \\
\text { neck 100) }\end{array}$ & III & Locally advanced HNSCC & Avelumab+SOC chemoRT vs SOC chemoRT & PSF and OS \\
\hline
\end{tabular}

AE, adverse events; DLT, dose limiting toxicity; DoR, duration of response; EFS, event free survival; HPV, Human papilloma virus; IMRT, intensity-modulated radiotherapy; ORR, overall response rate; OPC, oropharyngeal cancer; OS, overall survival; PFS, progression-free survival; RT, radiation therapy; R/M HNSCC, recurrent/metastatic head and neck squamous cell carcinoma; SOC, standard of care.

cetuximab and vorinostat (histone deacetylases inhibitor of the Fas/FasL-dependent activation-induced death of T cells). ${ }^{39}$

\section{PREDICTIVE BIOMARKERS OF RESPONSE}

Despite the positive results for ICI compared with chemotherapy, responses are seen in 30\% overall at best. Identifying the ideal biomarkers is crucial for optimizing and personalizing immunotherapy and remains an active area under investigation. The utility of PD-L1 expression as a biomarker has been variable across trials. Preliminary data have shown promise for alternative biomarkers such as high tumor mutation burden, which may explain the responses seen in PD-L1-negative patients. HPV-related patients with HNSCC have significantly longer survival than HPV-negative tumors ${ }^{40-43}$; however, the reasons for such outcome remain largely unknown. Nonetheless, it is known that HPV-associated HNSCC respond better to chemotherapy and radiotherapy and have better prognosis with surgery alone. ${ }^{44}{ }^{45}$ It is estimated that $50 \%-60 \%$ of human head and neck cancers express PD-L1. ${ }^{40}{ }^{46}$ It has also been reported that HPV-positive HNSCC are more heavily infiltrated by Treg cells and PD-1-positive T cells, and that these PD-1 expressing tumor infiltrating $\mathrm{T}$ cells correlate with better OS in HPV-associated head and neck cancer. ${ }^{40}$ In the phase Ib KEYNOTE-012 trial of pembrolizumab in R/M HNSCC, ORR and median OS were higher for PD-L1-positive patients (22\% vs $4 \%$ and 303 vs 151 days, respectively). ${ }^{17}$ Of note, PD-L1 positivity was defined by both tumor and immune cell expression $\geq 1 \%$. The 6-month OS rate was also higher for HPV-positive $(70 \%$ vs $56 \%)$. In the phase II KEYNOTE-055 trial evaluating pembrolizumab in R/M HNSCC refractory to platinum and cetuximab, response rates were similar irrespective of HPV status $(16 \%)$ but OS at 6 months was higher in HPV-associated disease (72\% vs $55 \%$ in HPV-negative disease). ${ }^{18}$ On the other hand, responses were higher based on PD-L1 status $(18 \%$ in PD-L1 $\geq 1 \%, 12 \%$ in PD-L1 $<1 \%$ and $27 \%$ in PD-L1 $\geq 50 \%)$. However, this did not translate into significant difference in PFS or OS. Although the phase III KEYNOTE-040 trial showed no benefit for pembrolizumab over chemotherapy in the intent-to-treat analysis, subgroup analysis showed superiority with increased PD-L1 expression. ${ }^{21}$ For instance, among PD-L1 $\geq 1 \%$ group, OS was 8.7 vs 7.1 months with chemotherapy $(\mathrm{HR}=0.75 ; \mathrm{p}=0.0078)$, whereas for PD-L1 expression $\geq 50 \%$ (which accounted for only $26 \%$ of patients), OS was 11.6 vs 7.9 months, respectively (HR 0.54; $\mathrm{p}=0.0017$ ). Similarly, extrapolated analysis of the CheckMate-141 phase III trial suggested higher benefit for nivolumab in patients with PD-L1 and HPV positive (which comprised $57 \%$ and $25 \%$ of the patients, respectively). ${ }^{21}$ Median OS was 8.7 vs 4.6 months among patients with $\mathrm{PD}-\mathrm{L} \geq 1 \%(\mathrm{HR}=0.55)$ and 5.7 vs 5.8 months $(\mathrm{HR}=0.89, \mathrm{p}=0.17)$ among those with $\mathrm{PD}-\mathrm{L} 1<1 \%$ for nivolumab and chemotherapy respectively. On the other hand, median OS was 9.1 vs 4.4 months $(\mathrm{HR}=0.56)$ in HPV-positive and 7.5 vs 5.8 months $(\mathrm{HR}=0.73, \mathrm{p}=0.55)$ for HPV-negative disease for nivolumab and chemotherapy, respectively. Table 1 summarizes the effect of HPV and PD-L1 status on response to ICI in the four published trials. 


\section{TOXICITY}

As shown across the trials above, the side-effect profile of ICI is significantly more favorable than traditional cytotoxic chemotherapy and is similar to what is seen with their use in other indications. They are generally well tolerated with fatigue $(\sim 20 \%)$ and nausea (9\%) being the most common AEs. However, given their unique mechanism of action, severe immune-mediated reactions can occur and include but are not limited to: thyroiditis, pneumonitis, hepatitis, colitis, nephritis, hypophysitis, myocarditis, myositis, neuritis, adrenal insufficiency, rash and neurological toxicities. Immune-mediated thyroiditis is the most commonly seen $(15 \%)$, whereas the others occur in $<5 \%$ of cases. Most of these reactions are transient and minor (grade 1 and 2). Nonetheless, grade $3 / 4$ can still occur in $\sim 1 \%-2 \%$ of the cases and may be fatal in some of them. As future combinations with PD-1 and CTLA-4 inhibitors are being explored in HNSCC, additive toxicity is expected, in keeping with what has been reported in other solid tumors such as melanoma. Management depends on the type and severity of the immune-mediated reaction, but generally involves holding or discontinuing the immunotherapy and administering high-dose steroids with a slow taper over weeks to months until the toxicity decreases to grade 1 or completely resolves. Some cases require more potent immunosuppressants such as mycophenolate mofetil and infliximab (although the latter is contraindicated in immune-mediated hepatitis). Clear guidelines on the management of ICI toxicities have now been published by many oncological societies (American Society of Clinical Oncology and Society for Immuno-Therapy of Cancer).

\section{CONCLUSION}

These are exciting times for immunotherapy in oncology. Immune checkpoint inhibitors continue to garner new indications in different malignancies and various treatment settings. R/M HNSCC has dismal prognosis with median survival ranging between 6 and 12 months. Over the last decade, there has been minimal therapeutic advancement until the recent approvals of pembrolizumab and nivolumab beyond first-line chemotherapy. These novel therapies are of unique mechanism of action and thus also have unique adverse effects. They can in some cases, provide durable responses that we have never seen with standard chemotherapy and are generally well tolerated with the caveat of minimal risk of life-threatening immune reactions. Unfortunately, only $\sim 20 \%$ of the patients respond, highlighting the need to identify more reliable biomarkers than PD-L1 that can improve patient selection and help predict response. Trials of ICI in first line, adjuvant and in combination with other therapeutic modalities (chemotherapy, radiotherapy) are also under investigation and results have yet to determine the role ICI may play in treatment of HSNCC.

\section{Acknowledgements The authors would like to thank Irisa Tam for creating} the figures.

Contributors BS conceived, designed and directed this review paper. BS did most of the literature review and writing. ET and BB contributed to the literature review and writing. IS critically reviewed and corrected the final version of the submitted manuscript.

Funding This research received no specific grant from any funding agency in the public, commercial or not-for-profit sectors.
Competing interests None declared.

Patient consent Not required.

Provenance and peer review Commissioned; externally peer reviewed.

C American Federation for Medical Research (unless otherwise stated in the text of the article) 2018. All rights reserved. No commercial use is permitted unless otherwise expressly granted.

\section{REFERENCES}

1 Siegel RL, Miller KD, Jemal A. Cancer Statistics, 2017. CA Cancer J Clin 2017;67:7-30.

2 Sacco AG, Cohen EE. Current Treatment Options for Recurrent or Metastatic Head and Neck Squamous Cell Carcinoma. J Clin Oncol 2015;33:3305-13.

3 Vermorken JB, Mesia R, Rivera F, et al. Platinum-based chemotherapy plus cetuximab in head and neck cancer. N Engl J Med 2008;359:1116-27.

4 Tong CC, Kao J, Sikora AG. Recognizing and reversing the immunosuppressive tumor microenvironment of head and neck cancer. Immunol Res 2012;54(13):266-74.

5 Dunn GP, Old LJ, Schreiber RD. The immunobiology of cancer immunosurveillance and immunoediting. Immunity 2004;21:137-48.

6 Vesely MD, Kershaw MH, Schreiber RD, et al. Natural innate and adaptive immunity to cancer. Annu Rev Immunol 2011;29:235-71.

7 Strauss L, Bergmann C, Gooding W, et al. The frequency and suppressor function of CD4+CD25highFoxp3+ T cells in the circulation of patients with squamous cell carcinoma of the head and neck. Clin Cancer Res 2007; 13:6301-11.

8 Chikamatsu K, Sakakura K, Whiteside TL, et al. Relationships between regulatory $T$ cells and $C D 8+$ effector populations in patients with squamous cell carcinoma of the head and neck. Head Neck 2007;29:120-7.

9 Ferris RL, Hunt JL, Ferrone S, antigen Hleukocyte. Human leukocyte antigen (HLA) class I defects in head and neck cancer: molecular mechanisms and clinical significance. Immunol Res 2005;33:113-34.

10 Ferris RL, Whiteside TL, Ferrone S. Immune escape associated with functional defects in antigen-processing machinery in head and neck cancer. Clin Cancer Res 2006;12:3890-5.

11 Ferris RL. Immunology and Immunotherapy of Head and Neck Cancer. J Clin Oncol 2015;33:3293-304.

12 Pardoll DM. The blockade of immune checkpoints in cancer immunotherapy. Nat Rev Cancer 2012;12:252-64.

13 Zandberg DP, Strome SE. The role of the PD-L1:PD-1 pathway in squamous cell carcinoma of the head and neck. Oral Oncol 2014;50:627-32.

14 Lyford-Pike S, Peng S, Young GD, et al. Evidence for a role of the PD-1:PD-L1 pathway in immune resistance of HPV-associated head and neck squamous cell carcinoma. Cancer Res 2013;73:1733-41.

15 McCoy KD, Le Gros G. The role of CTLA-4 in the regulation of T cell immune responses. Immunol Cell Biol 1999;77:1-10.

16 Ferris RL, Blumenschein G, Fayette J, et al. Nivolumab for Recurrent SquamousCell Carcinoma of the Head and Neck. N Engl J Med 2016;375:1856-67.

17 Chow LQM, Haddad R, Gupta S, et al. Antitumor Activity of Pembrolizumab in Biomarker-Unselected Patients With Recurrent and/or Metastatic Head and Neck Squamous Cell Carcinoma: Results From the Phase lb KEYNOTE-012 Expansion Cohort. J Clin Oncol 2016;34:3838-45.

18 Bauml J, Seiwert TY, Pfister DG, et al. Pembrolizumab for Platinum- and Cetuximab-Refractory Head and Neck Cancer: Results From a Single-Arm, Phase II Study. J Clin Oncol 2017;35:1542-9.

19 Bauman JE, Cohen E, Ferris RL, et al. Immunotherapy of head and neck cancer: Emerging clinical trials from a National Cancer Institute Head and Neck Cancer Steering Committee Planning Meeting. Cancer 2016.

20 Seiwert TY, Burtness B, Mehra R, et al. Safety and clinical activity of pembrolizumab for treatment of recurrent or metastatic squamous cell carcinoma of the head and neck (KEYNOTE-012): an open-label, multicentre, phase 1b trial. Lancet Oncol 2016;17:956-65.

21 Pembrolizumab CEE. pembro) vs standard of care (SOC) for recurrent or metastatic head and neck squamous cell carcinoma (R/M HNSCC): Phase 3 KEYNOTE-040 trial. ESMO Congress; Madrid, Spain 2017.

22 Brahmer JR, Drake CG, Wollner I, et al. Phase I study of single-agent antiprogrammed death-1 (MDX-1106) in refractory solid tumors: safety, clinical activity, pharmacodynamics, and immunologic correlates. J Clin Oncol 2010;28:3167-75.

23 Topalian SL, Hodi FS, Brahmer JR, et al. Safety, Activity, and Immune Correlates of Anti-PD-1 Antibody in Cancer. N Engl J Med Overseas Ed 2012;366:2443-54.

24 Harrington KJ, Ferris RL, Blumenschein G, et al. Nivolumab versus standard, single-agent therapy of investigator's choice in recurrent or metastatic 
squamous cell carcinoma of the head and neck (CheckMate 141): healthrelated quality-of-life results from a randomised, phase 3 trial. Lancet Oncol 2017;18:1104-15.

25 Segal SIO NH, Balmanoukian AS, Massarelli E, et al. Clinical activity and safety of MEDI4736, an anti-PD-L1 antibody, In Head and neck cancer. ESMO 2016. Congress.

26 Zandberg. Durvalumab for recurrent/metastatic (R/M) head and neck squamous cell carcinoma (HNSCC): preliminary results from a single-arm, phase 2 study. ESMO 2017. Congress.

27 Wolchok JD, Rollin L, Larkin J. Nivolumab and Ipilimumab in Advanced Melanoma. New Engl J Med 2017;377:2503-4.

28 Motzer RJ, Tannir NM, McDermott DF, et al. Nivolumab plus Ipilimumab versus Sunitinib in Advanced Renal-Cell Carcinoma. N Engl J Med Overseas Ed 2018;378:1277-90

29 Jie HB, Schuler PJ, Lee SC, et al. CTLA-4(+) Regulatory T Cells Increased in Cetuximab-Treated Head and Neck Cancer Patients Suppress NK Cell Cytotoxicity and Correlate with Poor Prognosis. Cancer Res 2015;75:2200-10.

30 Parikh F, Duluc D, Imai N, et al. Chemoradiotherapy-induced upregulation of PD-1 antagonizes immunity to HPV-related oropharyngeal cancer. Cancer Res 2014;74:7205-16.

31 Vincent J, Mignot G, Chalmin F, et al. 5-Fluorouracil selectively kills tumorassociated myeloid-derived suppressor cells resulting in enhanced T celldependent antitumor immunity. Cancer Res 2010;70:3052-61.

32 Ghiringhelli F, Larmonier N, Schmitt E, et al. CD4+CD25+ regulatory T cells suppress tumor immunity but are sensitive to cyclophosphamide which allows immunotherapy of established tumors to be curative. Eur J Immunol 2004;34:336-44.

33 Brix N, Tiefenthaller A, Anders H, et al. Abscopal, immunological effects of radiotherapy: Narrowing the gap between clinical and preclinical experiences. Immunol Rev 2017;280:249-79.

34 Rice AE, Latchman YE, Balint JP, et al. An HPV-E6/E7 immunotherapy plus PD-1 checkpoint inhibition results in tumor regression and reduction in PD-L1 expression. Cancer Gene Ther 2015;22:454-62.
35 Lynch DH. The promise of 4-1BB (CD137)-mediated immunomodulation and the immunotherapy of cancer. Immunol Rev 2008;222:277-86.

36 Weinberg AD, Rivera MM, Prell R, et al. Engagement of the $0 X-40$ receptor in vivo enhances antitumor immunity. J Immunol 2000;164:2160-9.

37 Bell RB, Leidner RS, Crittenden MR, et al. OX40 signaling in head and neck squamous cell carcinoma: Overcoming immunosuppression in the tumor microenvironment. Oral Oncol 2016;52:1-10.

38 Deng WW, Mao L, Yu GT, et al. LAG-3 confers poor prognosis and its blockade reshapes antitumor response in head and neck squamous cell carcinoma. Oncoimmunology 2016;5:e1239005.

39 Gillenwater AM, Zhong M, Lotan R. Histone deacetylase inhibitor suberoylanilide hydroxamic acid induces apoptosis through both mitochondrial and Fas (Cd95) signaling in head and neck squamous carcinoma cells. Mol Cancer Ther 2007:6:2967-75

40 Badoual C, Hans S, Merillon N, et al. PD-1-expressing tumor-infiltrating T cells are a favorable prognostic biomarker in HPV-associated head and neck cancer. Cancer Res 2013;73:128-38.

41 Ang KK, Harris J, Wheeler R, et al. Human Papillomavirus and Survival of Patients with Oropharyngeal Cancer. N Engl I Med Overseas Ed 2010;363:24-35

42 Marur S, D'Souza G, Westra WH, et al. HPV-associated head and neck cancer: a virus-related cancer epidemic. Lancet Oncol 2010;11:781-9.

43 Fakhry C, Westra WH, Li S, et al. Improved survival of patients with human papillomavirus-positive head and neck squamous cell carcinoma in a prospective clinical trial. J Natl Cancer Inst 2008;100:261-9.

44 Chung $\mathrm{CH}$, Gillison ML. Human papillomavirus in head and neck cancer: its role in pathogenesis and clinical implications. Clin Cancer Res 2009; 15:6758-62.

45 Fisher JW, Thompson BM, Garcia AD. Integrative clinical experience: an innovative program to prepare for internship. Teach Learn Med 2007;19:302-7.

46 Strome SE, Dong H, Tamura H, et al. B7-H1 blockade augments adoptive T-cell immunotherapy for squamous cell carcinoma. Cancer Res 2003;63:6501-5. 